\title{
Regeneração de defeito ósseo crítico após implantação de fosfato de cálcio bifásico ( $\beta$-fosfato tricálcico/pirofosfato de cálcio) e vidro bioativo fosfatado
}

\section{(Regeneration of a critical bone defect after implantation of biphasic calcium phosphate - $\beta$-tricalcium phosphate/calcium pyrophosphate - and phosphate bioactive glass)}

\author{
R. S. Almeida' ${ }^{1 *}$ M. H. Prado da Silva ${ }^{2}$, D. Navarro da Rocha ${ }^{2}$, I. I. A. Ribeiro', \\ A.A. Barbosa Júnior ${ }^{3}$, F. B. Miguel ${ }^{4}$, F. P. Rosa ${ }^{1}$ \\ ${ }^{1}$ Universidade Federal da Bahia, Instituto de Ciências da Saúde, Laboratório de Bioengenharia Tecidual e \\ Biomateriais, Av. Reitor Miguel Calmon s/n, 40110-100, Salvador, BA, Brasil \\ ${ }^{2}$ Instituto Militar de Engenharia, Seção de Engenharia Mecânica e de Materiais, Rio de Janeiro, RJ, Brasil \\ ${ }^{3}$ Fundação Oswaldo Cruz, Instituto Gonçalo Moniz, Salvador, BA, Brasil \\ ${ }^{4}$ Universidade Federal do Recôncavo da Bahia, Centro de Ciências da Saúde, Santo Antônio de Jesus, BA, Brasil
}

Resumo

\begin{abstract}
Objetivou-se avaliar novos biomateriais fosfatados para regeneração de defeito ósseo crítico. Distribuíram-se 45 ratos Wistar em três grupos: CON (sem implantação de biomaterial), FCB (grânulos de fosfato de cálcio bifásico: fosfato tricálcico tipo $\beta, \beta$-TCP/ pirofosfato de cálcio) e FCB/BV (FCB/vidro bioativo fosfatado), avaliados aos 15, 45 e 120 dias de pós-operatório. No grupo CON, observaram-se neoformação óssea restrita às bordas ósseas e preenchimento do defeito por delgado tecido conjuntivo fibroso. Em FCB e FCB/BV, os grânulos preencheram toda a extensão do defeito e apresentaram maior fragmentação em FCB/BV. A neoformação óssea foi mais evidente no FCB. De permeio às partículas dos biomateriais formou-se um tecido conjuntivo frouxo, que evoluiu para fibroso em FCB. Os biomateriais desencadearam discreta reação inflamatória crônica granulomatosa, que se tornou inconspícua. Conclui-se que os materiais foram biocompatíveis, atuaram como arcabouços tridimensionais, apresentaram potencial osteocondutor e favoreceram a regeneração óssea, principalmente FCB. A adição do vidro bioativo aumentou a biodegradabilidade de FCB/BV. Palavras-chave: biomateriais, implantes experimentais, fosfatos de cálcio, regeneração óssea.
\end{abstract}

\begin{abstract}
The objective was to evaluate new phosphate biomaterials for the regeneration of a critical bone defect. 45 Wistar rats were distributed in three groups: CON (without biomaterial implantation), FCB (biphasic calcium phosphate granules: $\beta$-tricalcium phosphate, $\beta-T C P /$ calcium pyrophosphate) and FCB/BV (FCB/bioactive glass granules), evaluated at 15 , 45, and 120 postoperative days. In the CON group, bone neoformation restricted to bone edges and filling of the defect by thin fibrous connective tissue were observed. In $F C B$ and $F C B / B V$, the granules filled the entire extent of the defect and showed greater fragmentation in $F C B / B V$. Bone neoformation was more evident in FCB. From the biomaterial particles, a loose connective tissue was formed, which evolved to fibrous in FCB. Biomaterials triggered a discrete chronic inflammatory granulomatous reaction, which became inconspicuous. It was concluded that materials were biocompatible, acted as three-dimensional scaffolds, presented osteoconductive potential, and favored bone regeneration, especially FCB. The addition of bioactive glass increased the biodegradability of FCB/BV.
\end{abstract}

Keywords: biomaterials, experimental implants, calcium phosphates, bone regeneration.

\section{INTRODUÇÃO}

Situações em que ocorrem grandes perdas ósseas, por exemplo após as ressecções de tumores e fraturas extensas, o reparo tecidual ocorre de forma limitada, demandando o uso de enxertos [1]. Como alternativa, a bioengenharia tecidual

*renata.almeidabio@gmail.com

Dhttps://orcid.org/0000-0001-8359-6345 tem desenvolvido biomateriais para atuar como substitutos ósseos e proporcionar o restabelecimento funcional e estético, para reinserção social e laboral destes indivíduos [2]. Há um consenso que o termo biomaterial refere-se a materiais que podem interagir com sistemas biológicos para avaliar, tratar, aumentar ou substituir qualquer tecido, órgão ou função do corpo [3]. De maneira clássica, em relação à sua composição química, estes materiais podem ter origem metálica, cerâmica, polimérica ou compósitos - uma 
combinação destes [4]. Porém, recentemente esta definição vem sendo refutada e discutida de forma mais abrangente, considerando-se os biomateriais como substâncias desenvolvidas de forma que, sozinha ou como parte de um sistema complexo, podem ser usadas para direcionar, pelo controle de interações com componentes de sistemas vivos, qualquer procedimento terapêutico ou diagnóstico, em humanos ou medicina veterinária, podendo incluir tecidos engenheirados, células, órgãos e até vírus [4].

Os biomateriais cerâmicos são amplamente utilizados por exibirem ângulos de contato de $60-85^{\circ}$ com a água e, portanto, não induz mudanças conformacionais nas proteínas plasmáticas adsorvidas, o que promove a migração e adesão celular [2]. Dentre estes o $\beta$-fosfato tricálcico ( $\beta$-TCP) é utilizado nas técnicas regenerativas como componente de cimentos biológicos ou como reforço de arcabouços poliméricos [5], devido à sua semelhança com componentes inorgânicos do tecido ósseo, não apresentar risco de transmissão de doenças, ter boa biocompatibilidade e participar do equilíbrio cálcio/fósforo do organismo [6]. Além do $\beta$-TCP, o pirofosfato de cálcio $\left(\mathrm{Ca}_{2} \mathrm{P}_{2} \mathrm{O}_{7}\right)$ também vem sendo utilizado como um substituto ósseo reabsorvível, biocompatível e não tóxico [7, 8]. Ao apresentar uma razão molar $\mathrm{Ca} / \mathrm{P}$ de 1,0 , o $\mathrm{Ca}_{2} \mathrm{P}_{2} \mathrm{O}_{7}$ exibe uma maior taxa de reabsorção do que a do $\beta$-TCP $(\mathrm{Ca} / \mathrm{P}=1,5)$ e vem sendo indicado como uma possível alternativa às fases hidroxiapatita e $\beta$-TCP para a regeneração óssea [9]. Já os vidros bioativos são promissores devido à sua capacidade de ligar-se quimicamente ao tecido ósseo, sem formar tecido de interposição, o que estimula a neoformação tecidual e a regeneração [10]. São compostos principalmente por sílica, cálcio, sódio e fósforo, sendo os vidros bioativos fosfatados mais fácies de fundir e quimicamente mais instáveis que os silicatos, o que favorece sua biodegradação e bioabsorção [11]. Quando em contato com fluidos biológicos, os vidros bioativos formam um hidroxicarbonato de apatita semelhante à hidroxiapatita do tecido ósseo [12], que tem afinidade por fatores de crescimento que interagem com macrófagos e estes exibem forte gradiente químico para células progenitoras de osteoblastos [10].

Estas cerâmicas exibem excelentes propriedades de biorreabsorção, osteocondução, osteoindução e osteogênese. Quando utilizadas de forma isolada são geralmente projetadas para preenchimento ósseo ou como revestimento bioativo em implantes metálicos [13]; desta forma, esperase que a incorporação de $5 \%$ de vidro bioativo ao $\beta$-TCP e ao pirofosfato de cálcio proporcione a vantagem adicional da bioatividade aumentada em conjunto com a estabilidade mecânica melhorada [14]. Outro fator de grande relevância é que os biomateriais devem ser fabricados com propriedades adequadas ao tecido que se pretende reparar, juntamente com suas exigências geométricas [1]. Sendo assim, os grânulos são muito favoráveis, por formarem um arcabouço que permite a adesão e a migração celular, por serem de fácil manuseio e capazes de preencher o defeito [15]. Além disso, as propriedades dos biomateriais devem ser sempre avaliadas e os testes in vivo permitem estudar as interações teciduais previamente à sua aplicação clínica, visto que o método de fabricação, a composição química e o formato podem interferir no comportamento celular e na interface biomaterial/tecido. Diante do exposto, este trabalho avaliou a biocompatibilidade e a biofuncionalidade de grânulos de biomateriais de fosfato de cálcio bifásico ( $\beta$-fosfato tricálcico/pirofosfato de cálcio) e vidro bioativo fosfatado, como novas composições para regeneração de defeito ósseo crítico.

\section{MATERIAL E MÉTODOS}

Este estudo foi previamente aprovado pela Comissão de Ética no Uso de Animais (protocolo 38/2012) do Instituto de Ciências da Saúde da Universidade Federal da Bahia e seguiu as Normas Éticas de Pesquisas em Animais (Lei ${ }^{\circ}$ 11794 de 2008), bem como as diretrizes do Instituto Nacional de Saúde para o cuidado e uso de animais de laboratório (NIH Publicação $\mathrm{n}^{\circ}$ 85-23 Rev. 1985). Os biomateriais utilizados foram produzidos e caracterizados seguindo protocolo descrito na literatura [16, 17]. Os biomateriais foram produzidos pelo método de deposição química, onde esponjas poliméricas de poliuretano foram imersas em uma solução rica em íons de cálcio $\left(\mathrm{Ca}^{2+}\right)$ e fosfato $\left(\mathrm{PO}_{4}^{3-}\right)$, com razão molar $\mathrm{Ca} / \mathrm{P}=1,67$, a $80{ }^{\circ} \mathrm{C}$, com trocas durante três dias até a completa deposição de monetita $\left(\mathrm{CaHPO}_{4}\right)$. Após a deposição, foi realizada a etapa de conversão alcalina, onde as esponjas recobertas pela monetita foram imersas em solução $0,1 \mathrm{~mol} / \mathrm{L}$ de hidróxido de potássio $(\mathrm{KOH}$, Merck, Alemanha) a $60{ }^{\circ} \mathrm{C}$ por $24 \mathrm{~h}$. As amostras foram levadas ao forno (LF914, Jung, Brasil) e aquecidas até $900{ }^{\circ} \mathrm{C}$, onde a esponja polimérica foi volatizada, dando origem ao arcabouço cerâmico poroso de fosfato de cálcio bifásico [fosfato tricálcico do tipo $\beta$ ( $\beta$-TCP) + pirofosfato de cálcio $\left.\left(\mathrm{Ca}_{2} \mathrm{P}_{2} \mathrm{O}_{7}\right)\right]$.

$\mathrm{O}$ vidro bioativo fosfatado $\left(\mathrm{P}_{2} \mathrm{O}_{5}-\mathrm{CaO}-\mathrm{CaF}_{2}\right)$ foi projetado para ter a seguinte composição (em mol): $60 \%$ de pentóxido de fósforo $\left(\mathrm{P}_{2} \mathrm{O}_{5}\right)+20 \%$ de óxido de cálcio $(\mathrm{CaO})+20 \%$ de fluoreto de cálcio $\left(\mathrm{CaF}_{2}\right)$. A fonte do $\mathrm{P}_{2} \mathrm{O}_{5}$ utilizada foi o ácido ortofosfórico $\left(\mathrm{H}_{3} \mathrm{PO}_{4}\right.$, Merck, Alemanha), enquanto a fonte de $\mathrm{CaO}$ foi o carbonato de cálcio $\left(\mathrm{CaCO}_{3}\right.$, Sigma Aldrich, Alemanha), e para o fluoreto de cálcio utilizou-se um reagente analítico $\left(\mathrm{CaF}_{2}\right.$, Sigma Aldrich, Alemanha). Estes reagentes foram misturados e homogeneizados em uma placa com agitação magnética (Q261M12, Quimis, Brasil) por 24 h, seguido de secagem em estufa a $60^{\circ} \mathrm{C}$ por $6 \mathrm{~h}$. A mistura foi fundida em um forno a $1400{ }^{\circ} \mathrm{C}$, usando um cadinho de platina, com patamar de 2 h e taxa de aquecimento de $5{ }^{\circ} \mathrm{C} / \mathrm{min}$. O fundido foi retirado rapidamente do forno e vertido para um recipiente contendo água destilada, para formação de partículas de vidro (frita), que em seguida foram trituradas em um moinho de bola (MA 350, Marconi, Brasil). Estas partículas de vidro bioativo fosfatado foram classificadas em um sistema de peneiras da série Tyler, para então se selecionar uma distribuição de tamanhos inferiores a $20 \mu \mathrm{m}$ (500 mesh). As partículas foram peneiradas em fluxo contínuo de álcool etílico (Vetec, 
Brasil) para facilitar a passagem do material pela peneira. Posteriormente, à metade dos arcabouços cerâmicos porosos de fosfato de cálcio bifásico $\left(\beta-\mathrm{TCP}+\mathrm{Ca}_{2} \mathrm{P}_{2} \mathrm{O}_{7}\right)$ foram adicionados $5 \%$ do vidro bioativo fosfatado. Por fim, todos os arcabouços cerâmicos porosos foram sinterizados a 1200 ${ }^{\circ} \mathrm{C}$ para consolidação da estrutura cerâmica. Os arcabouços formados foram fragmentados e classificados utilizando-se peneiras com aberturas na faixa de 0,5 a $0,7 \mathrm{~mm}$. Em seguida os grânulos de fosfato de cálcio bifásico (grupo $\mathrm{FCB}$ ) e de fosfato de cálcio bifásico/vidro bioativo (grupo $\mathrm{FCB} / \mathrm{BV}$ ) foram acondicionados em eppendorfs e esterilizados com 15 kGy de radiação gama.

Caracterização dos materiais: para a identificação das fases cristalinas dos arcabouços porosos, utilizou-se um difratômetro da PANalytical, X'Pert PRO MPD. A varredura foi realizada no intervalo $10^{\circ}<2 \theta<80^{\circ}$ com uma fenda incidente de $1^{\circ}$ e divergente de $1 / 2^{\circ}$, tempo por passo de $100 \mathrm{~s}$ e passo de coleta de $0,02^{\circ}$ com uma fonte de cobre e potência de $40 \mathrm{kV}$ e $40 \mathrm{~mA}$. A análise quantitativa de fases, através do refinamento pelo método de Rietveld, foi realizada utilizando o programa X'Pert HighScore Plus (PANalytical) e foram obtidas as frações de fases cristalinas dos arcabouços porosos antes e após a etapa de conversão alcalina, bem como dos grânulos sinterizados com (grupo FCB/BV) e sem vidro bioativo (grupo FCB). A análise da morfologia superficial dos arcabouços porosos e grânulos obtidos foi realizada em um microscópio eletrônico de varredura (MEV, JSM 5800LV, Jeol).

Ensaio in vivo: para implantação dos biomateriais utilizaram-se 45 Rattus novergicus Wistar, machos adultos, com massa corpórea entre 350 e 400 g distribuídos aleatoriamente para composição de três grupos: CON (defeito vazio, preenchimento apenas com o coágulo sanguíneo); FCB (grânulos de fosfato de cálcio bifásico) e FCB/BV (grânulos de fosfato de cálcio bifásico/vidro bioativo). O procedimento cirúrgico para confecção do defeito ósseo crítico foi o mesmo descrito em outros trabalhos do grupo [18-20]. Após remoção do fragmento ósseo os biomateriais foram implantados de acordo com seus respectivos grupos experimentais, exceto para o grupo controle. Ao final, o retalho cutâneo foi reposicionado e suturado com pontos simples (Fig. 1). Aos 15, 45 e 120 dias de pós-cirúrgico, os animais foram eutanasiados com dose letal do anestésico para remoção da calvária. Os espécimes foram fixados em formaldeído tamponado a $4 \%$ (Aldrich, Reino Unido) por no mínimo $72 \mathrm{~h}$ e descalcificados com ácido nítrico a 7\% (Aldrich, Reino Unido) durante 7 dias para o processamento histológico. Após a inclusão em parafina, foram realizados cortes transversais de forma seriada com $7 \mu \mathrm{m}$ de espessura e corados com hematoxilinaeosina (HE), picrosirius-red (PIFG) e tricrômico de MassonGoldner (TMG) [20]. A análise histomorfométrica foi realizada por microscopia óptica utilizando microscópio MM6B (Leica, Alemanha) acoplado a uma câmera digital DFC7000T (Leica, Alemanha) e o sistema de análise de processamento de imagens LAS Core (Leica, Alemanha). Foram realizadas as medidas de extensão linear do defeito (em $\mathrm{mm}$ ), porcentagem de preenchimento linear do defeito por matriz óssea neoformada mineralizada e área seccional neomineralizada em relação à área seccional total do defeito [20].

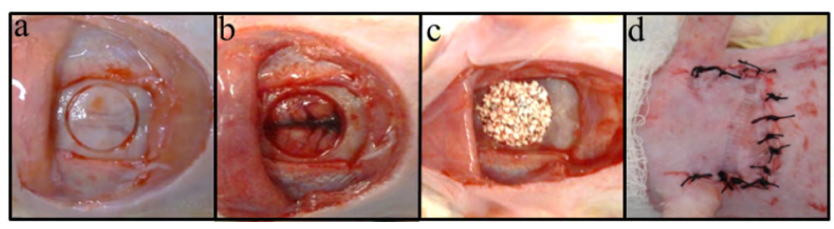

Figura 1: Fotos das etapas do procedimento cirúrgico evidenciando a demarcação do defeito (a) e remoção do fragmento ósseo (b) para implantação dos biomateriais (c), seguido de reposicionamento do retalho e sutura (d).

[Figure 1: Pictures of the steps of the surgical procedure showing the demarcation of the defect (a) and removal of the bone fragment (b) for implantation of biomaterials (c), followed by flap repositioning and suture $(d)$.]

\section{RESULTADOS E DISCUSSÃO}

De acordo com os resultados obtidos por difração de raios $\mathrm{X}(\mathrm{DRX})$, a técnica de deposição química produziu um recobrimento de monetita (JCPDS 01-070-1425) sobre as esponjas poliméricas (Fig. 2), que se apresenta como a fase termodinamicamente mais estável em condições ácidas, como a encontrada na solução precursora $(\mathrm{pH} 3,8)$ utilizada neste trabalho $[13,21]$. Durante a etapa de conversão alcalina, parte da fase monetita depositada foi transformada em hidroxiapatita (JCPDS 09-0432), 23,6\%, conforme a quantificação de fases obtida através do refinamento pelo método de Rietveld.Assim, majoritariamente o recobrimento sobre as esponjas poliméricas apresentou $76,4 \%$ da fase monetita. Após a volatilização das esponjas poliméricas a $900{ }^{\circ} \mathrm{C}$ e posterior fragmentação dos arcabouços porosos, os grânulos produzidos se apresentaram como um fosfato de cálcio bifásico, devido à identificação dos picos referentes às fases $\beta$-TCP (JCPDS 09-0169) e pirofosfato de cálcio (JCPDS 01-071-2123) nos difratogramas das amostras (Figs. 2c e 2d). A análise quantitativa de fases indicou $53,1 \%$ de pirofosfato de cálcio e $46,9 \%$ de $\beta$-TCP para os grânulos do grupo FCB. Para o grupo FCB/BV, a adição do vidro bioativo fosfatado aumentou a quantidade da fase $\beta$-TCP para $55,2 \%$, enquanto houve uma diminuição no teor de pirofosfato de cálcio para 46,8\%.É estabelecida na literatura a transformação da fase monetita para o pirofosfato de cálcio após o tratamento térmico acima de $800^{\circ} \mathrm{C}[22,23]$. Recentes estudos vêm utilizando clinicamente o pirofosfato de cálcio e o fosfato tricálcico $(\beta$ e $\alpha)$ devido ao maior potencial bioativo, quando em comparação à fase hidroxiapatita [24, 25]. A bioatividade é uma propriedade que está diretamente relacionada com a dissolução dos fosfatos de cálcio [21]. Por isso, atualmente é verificada uma crescente demanda na produção de fosfatos de cálcio com maior capacidade osteocondutora e bioatividade, consequência de uma adequada biorreabsorção em meio fisiológico.

Na Fig. 3a é possível observar que a superfície da monetita depositada sobre as esponjas poliméricas se apresentou 


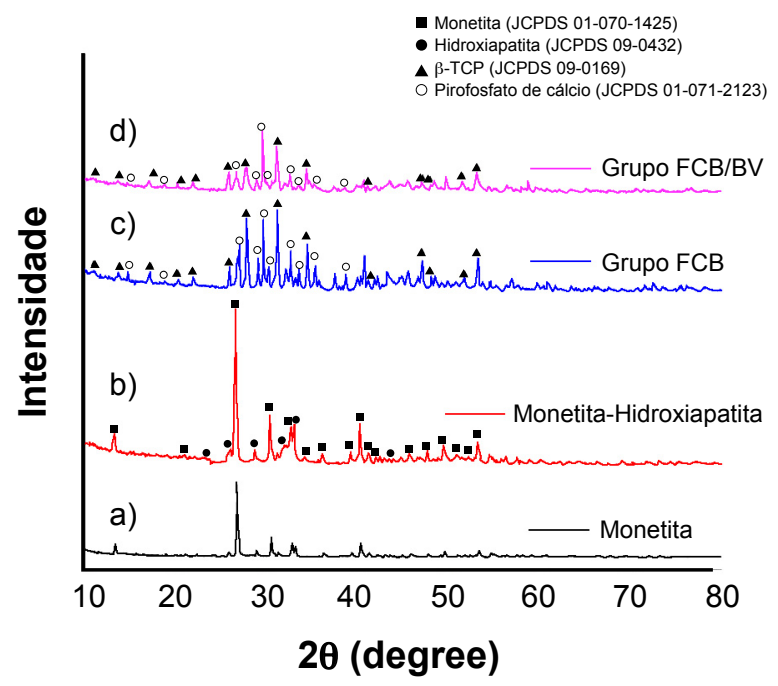

Figura 2: Difratogramas de raios $\mathrm{X}$ das amostras: a) monetita; b) monetita-hidroxiapatita; c) grupo FCB; e d) grupo FCB/BV.

[Figure 2: X-ray diffraction patterns of the samples: a) monetite; b) monetite-hydroxyapatite; c) FCB group; and d) FCB/BV group.]

em morfologia de placas, em dimensão micrométrica, característica dessa fase ácida de fosfato de cálcio [13]. Após a etapa de conversão alcalina, uma precipitação parcial e superficial de hidroxiapatita confirmou os resultados obtidos por DRX (Fig. 3b). O estudo cinético e morfológico da etapa de conversão em meio alcalino, também utilizada no presente estudo, sugeriu que o processo de precipitação da hidroxiapatita ocorreu pela dissolução superficial da fase precursora com uma posterior nucleação e crescimento da hidroxiapatita [26]. Além disso, as análises por MEV demostraram uma maior densificação dos grânulos do grupo FCB/BV (Fig. 3d), quando comparado ao grupo FCB (Fig. 3c). Este resultado foi compatível com uma sinterização em
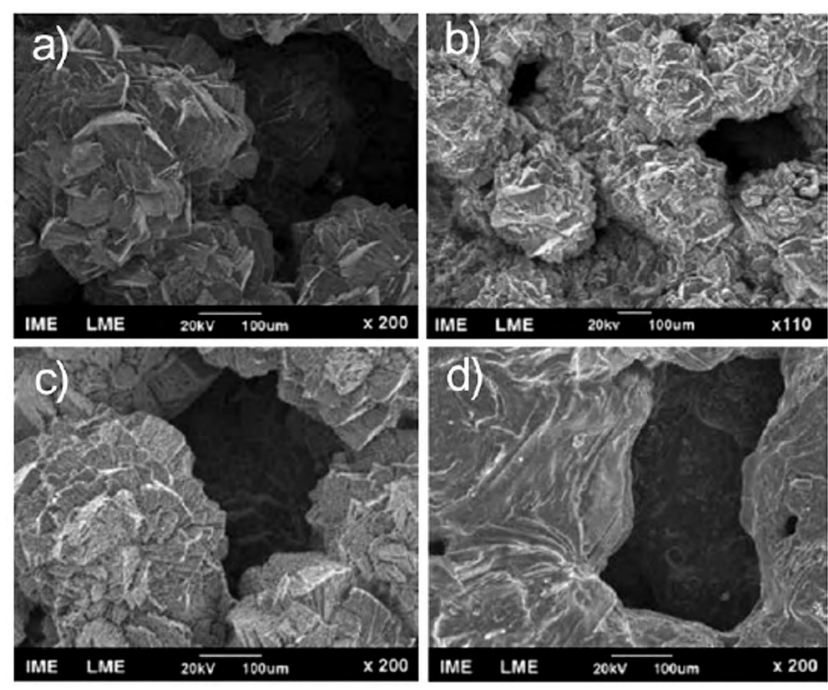

Figura 3: Micrografias de MEV das superfícies de: a) monetita; b) monetita-hidroxiapatita; c) grupo FCB; e d) grupo FCB/BV.

[Figure 3: SEM micrographs of the surfaces of: a) monetite; $b$ ) monetite-hydroxyapatite; c) FCB group; and d) FCB/BV group.] fase líquida, também observada em trabalhos anteriores [17].

Em estudos experimentais, a perda tecidual extensa pode ser observada com a confecção de defeito ósseo crítico, sem implantação de um arcabouço e nem aplicação de outra terapia regenerativa [18], como pode ser observado no grupo CON (defeito vazio). Em razão das especificidades dessa resposta e pela ausência de um suporte estrutural, neste grupo aos 15 dias a região de extensão do defeito foi preenchida por tecido conjuntivo fibroso bem vascularizado e com espessura inferior ao osso remanescente (Fig. 4a), que se tornou mais denso e com pouca vascularização aos 45 dias e com espessura mais delgada aos 120 dias (Fig. 4b) $[18,19]$. Esse tipo de reparo decorre da lesão tecidual causada pelo procedimento cirúrgico, em que há liberação de fatores de crescimento que atraem células fusiformes mesenquimais e induzem a diferenciação de fibroblastos para síntese do tecido conjuntivo [18]. Nestas situações, a regeneração óssea também é caracterizada por um processo reparativo e reacional à lesão tecidual, onde células osteoprogenitoras presentes no periósteo e no endósteo do osso adjacente são estimuladas a se proliferar e diferenciar em osteoblasto para produzir nova matriz óssea [12]. No grupo CON a neoformação óssea foi restrita às bordas do defeito, apresentando maior extensão aos 45 dias (Fig. 4c) e sem expansão aos 120 dias (Fig. 4d). Em contrapartida, nos grupos em que houve implantação dos biomateriais, FCB (grânulos de fosfato de cálcio bifásico) e FCB/BV (grânulos de fosfato de cálcio bifásico/vidro bioativo fosfatado), notouse aos 15 dias evidente neoformação óssea nas regiões de bordas e por condução entre as partículas do biomaterial, em direção radial, com maior expansão em FCB que preencheu aproximadamente $30 \%$ do defeito (Figs. $4 \mathrm{e}$ e $4 \mathrm{~g}$ ) e mais limitada em FCB/BV ( 15\%, Figs. 4f e 4h). Após 45 dias esta matriz osteoide tornou-se mais evidente, encontrandose em alguns animais desconectada das bordas e ocupando aproximadamente $60 \%$ do defeito em FCB (Fig. 5a) e $40 \%$ em FCB/BV (Fig. 5b). Já aos 120 dias houve regeneração em extensão de aproximadamente $80-90 \%$ do defeito em FCB (Fig. 5c) e $60 \%$ em FCB/BV (Fig. 5d). No presente trabalho, a maior quantidade da fase pirofosfato de cálcio no grupo FCB resultou em maior capacidade regenerativa de defeitos ósseos críticos, como observado no resultado da Fig. 5c. Esta extensão da neoformação óssea observada nos grupos em que houve implantação dos biomateriais (FCB e $\mathrm{FCB} / \mathrm{BV}$ ) está associada à propriedade de osteocondução, decorrente da presença de um suporte estrutural (partículas do biomaterial). As áreas de mineralização estavam em regiões próximas à dura-máter, fonte primária de células osteogênicas e de fatores osteoindutivos [27]. O biomaterial composto apenas por fosfato de cálcio bifásico $(\mathrm{FCB})$ parece ter estimulado uma melhor atuação dos osteoblastos para síntese de nova matriz osteoide, o que está em consonância com outros autores que utilizaram estes biomateriais isolados [28-30] ou em conjunto [31,32] e obtiveram ótimos resultados para regeneração de defeitos críticos.

No grupo FCB aos 15 dias, a região de extensão do defeito foi preenchida pelos grânulos do biomaterial 


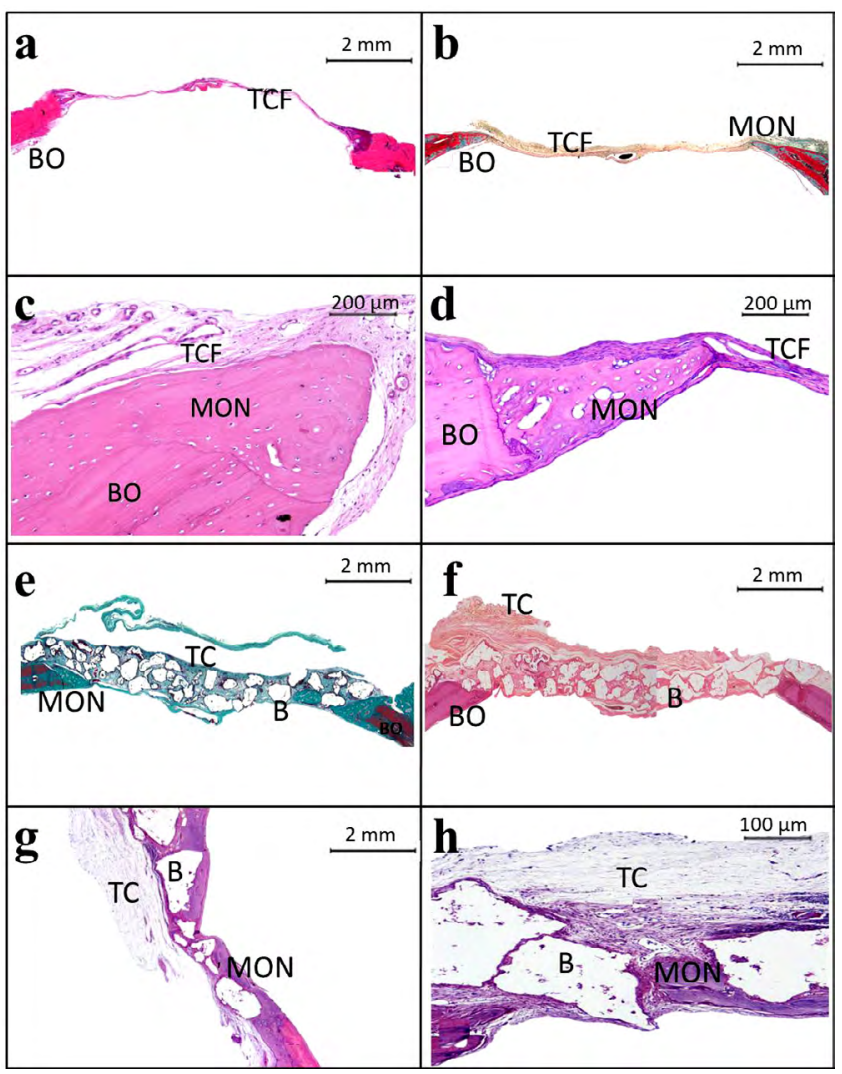

Figura 4: Fotomicrografias da região do defeito: a) CON em HE; b) CON em TMG; c) CON em HE; d) CON em HE; e) FCB em TMG; f) FCB/BV em PIFG; g) FCB em HE; h) FCB/BV em HE. Grupo $\mathrm{CON}$ : preenchimento do defeito por delgado tecido conjuntivo fibroso (TCF) aos 15 dias (a), que se tornou mais denso aos 120 dias (b); a neoformação óssea permaneceu restrita às bordas do defeito dos 15 dias (c) aos 120 dias (d). Grupos em que houve a implantação dos biomateriais: aos 15 dias notou-se evidente deposição de matriz osteoide (MON) nas regiões de bordas ósseas (BO) e por condução entre as partículas do biomaterial (e-h), com maior expansão em $\mathrm{FCB}(\mathrm{g})$; o preenchimento da região de extensão se deu pela organização tridimensional das partículas dos biomateriais (B) e por deposição de tecido conjuntivo (TC) bem vascularizado, principalmente próximo à veia central.

[Figure 4: Photomicrographs of the defect region: a) CON in HE; b) CON in TMG; c) CON in HE; d) CON in HE; e) FCB in TMG; f) $F C B / B V$ in PIFG; g) FCB in $H E$; h) FCB/BV in HE. CON group: defect was filled by thin fibrous connective tissue (TCF) at 15 days (a), which became denser after 120 days (b); bone neoformation remained restricted to the edges of the defect from 15 days (c) to 120 days $(d)$. Groups in which the biomaterials were implanted: at 15 days, osteoid matrix (MON) deposition was evident in the bone edge regions $(B O)$ and by conduction between the biomaterial particles $(e-h)$, with greater expansion in $F C B(g)$; the extension region was filled by the three-dimensional organization of the biomaterial particles $(B)$ and by the deposition of well-vascularized connective tissue (CT), especially near the central vein.]

(perdidos durante o processamento histológico, restando apenas espaços vazios com alguns resíduos), que possuíam formatos diversos e se organizaram de duas a quatro camadas (Fig. 4e). Em FCB/BV os espaços deixados foram mais homogêneos e demonstraram que as partículas se

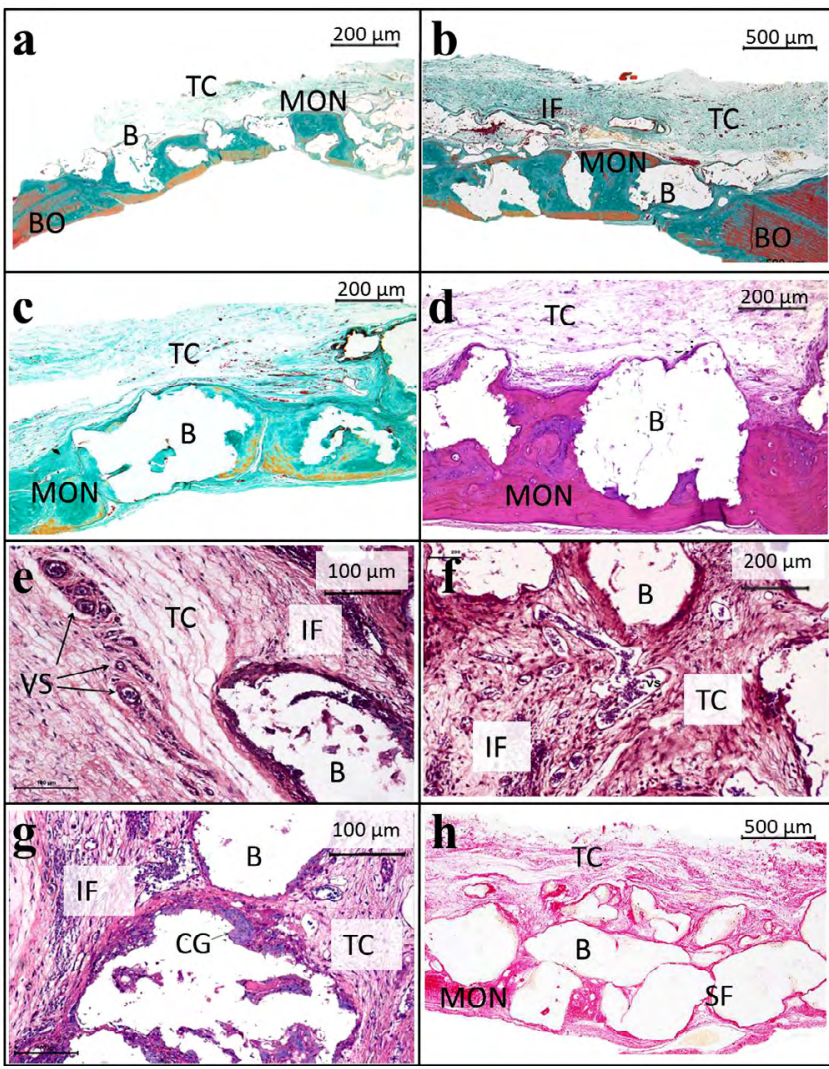

Figura 5: Fotomicrografias do reparo nos grupos em que houve implantação dos biomateriais (B): a) FCB em TMG; b) FCB/ BV em TMG; c) FCB em TMG; d) FCB/BV em HE; e) FCB em HE; f) FCB/BV em HE; g) FCB em HE; h) FCB/BV em PIFG. A neoformação de matriz osteoide (MON) a partir das bordas ósseas (BO) tornou-se mais evidente aos 45 dias $(\mathrm{a}, \mathrm{b})$, regenerando de $60-90 \%$ do defeito aos 120 dias (c,d), juntamente com intensa degradação das partículas. Aos 15 dias, de permeio às partículas, formou-se um tecido conjuntivo frouxo (TC) edemaciado, bem vascularizado e com presença de discreto a moderado infiltrado inflamatório mononuclear e discreta reação granulomatosa (IF) (e,f), com abundante presença de células gigantes multinucleadas (CG) (g). Aos 45 dias, este tecido conjuntivo tornou-se fibroso (TCF) em algumas regiões, com projeção de septos fibrosos (SF) circuncidando as partículas (h).

[Figure 5: Photomicrographs of the repair in the groups in which the biomaterials were implanted (B): a) FCB in $T M G$; b) $F C B$ / $B V$ in $T M G$; c) FCB in $T M G$; d) $F C B / B V$ in $H E$; e) $F C B$ in $H E$; f) $F C B / B V$ in $H E ; g) F C B$ in $H E ; h) F C B / B V$ in PIFG. The osteoid matrix neoformation (MON) from bone edges $(B O)$ became more evident at 45 days $(a, b)$, regenerating 60-90\% of the defect after 120 days $(c, d)$, together with intense particle degradation. At 15 days, permeating the particles, a loose, well-vascularized loose connective tissue (CT) was formed, with the presence of mild to moderate mononuclear inflammatory infiltrate and slight granulomatous reaction (IF) $(e, f)$, with an abundant presence of multinucleated giant cells $(C G)(\mathrm{g})$. After 45 days, this connective tissue became fibrous (TCF) in some regions, with a projection of fibrous septa $(S F)$ circumcising the particles $(h)$.]

organizaram de duas a três camadas, com espessura similar às bordas ósseas (Fig. 4f). No entanto, a permanência das partículas na região de implante durante todo o estudo e a perda do material durante o processamento histológico 
(corte) são indicadores da dureza dos grânulos, que pode ter sido decorrente do processo de sinterização a $1200{ }^{\circ} \mathrm{C}$ em que os biomateriais foram submetidos [33]. Entretanto, foi possível observar que a adição do vidro bioativo fosfatado influenciou na estabilidade química dos grânulos do grupo FCB/BV. A literatura ainda não possui um consenso sobre o mecanismo de dissolução dos vidros bioativos [34]. Dos 45 aos 120 dias, observou-se que as partículas sofreram intensa degradação, apresentando maior fragmentação e tamanhos muito reduzidos em FCB/BV (Fig. 5b) em comparação ao grupo FCB (Fig. 5a). Apesar da maior biodegradabilidade in vivo do grupo $\mathrm{FCB} / \mathrm{BV}$, um maior processo regenerativo não foi observado. Aos 45 dias, o tecido conjuntivo apresentou muita fibrose intersticial, com formação de septos fibrosos circuncidando as partículas, principalmente em FCB (Fig. 5h). Ainda foi possível observar a permanência de discreta inflamação mononuclear linfocitária e moderada reação inflamatória granulomatosa em FCB (Fig. 6a), entretanto em FCB/BV notou-se maior declínio da reação inflamatória com presença de poucas células mononucleares (Fig. 6b). Já aos 120 dias, o tecido conjuntivo ainda apresentava-se edemaciado (Figs. 6c e 6d) e tornou-se fibroso em FCB (Figs. 6c e 6e). Em ambos os grupos a reação inflamatória foi escassa, porém ainda com discreta reação crônica granulomatosa ao redor das partículas (Figs. 6e e 6f). No grupo CON, aos 15 dias foi possível visualizar discreto infiltrado inflamatório mononuclear distribuído de forma difusa, que se apresentou inconspícuo aos 45 dias e ausente aso 120 dias (Figs. 4a a 4c).

A faixa de tamanho dos grânulos $(0,5 \mathrm{a} 0,7 \mathrm{~mm})$ evitou que as partículas muito pequenas ocupassem os espaços entre as maiores, o que poderia reduzir o interstício e o potencial regenerativo devido à obstrução do espaço necessário para a migração celular e formação vascular [35]. A organização dos biomateriais com o tecido de preenchimento forneceu suporte estrutural para a proliferação de células e para o mecanismo de reparo, desenvolvendo espessura similar ao osso pré-existente em contraste ao grupo controle. Esses dados estão em consonância com diversos estudos que utilizaram biomateriais para regenerar defeito ósseo crítico [18-20]. A evolução do tecido conjuntivo frouxo para fibroso em FCB sugeriu que o biomaterial pode ser adequado para preenchimento de sulcos, partes moles, dentre outros sítios. O processo inflamatório observado em todos os grupos foi devido à liberação de citocinas e mediadores químicos após a lesão tecidual e vascular, que desencadeou uma cascata de reação inflamatória [18, 36, 37]. Nos grupos em que houve a implantação de biomateriais notou-se inflamação crônica granulomatosa do tipo corpo estranho, com a presença de células gigantes multinucleadas em torno das partículas em uma tentativa de degradar o biomaterial [36, 38]. A intensidade dessa resposta inflamatória foi relacionada com as características morfológicas e físico-químicas dos biomateriais, sendo a fase crônica essencial para determinar a biocompatibilidade e o tipo de reparo tecidual [35, 36]. Desta forma, ambos os biomateriais utilizados em nosso estudo foram biocompatíveis. Nossos achados contribuem

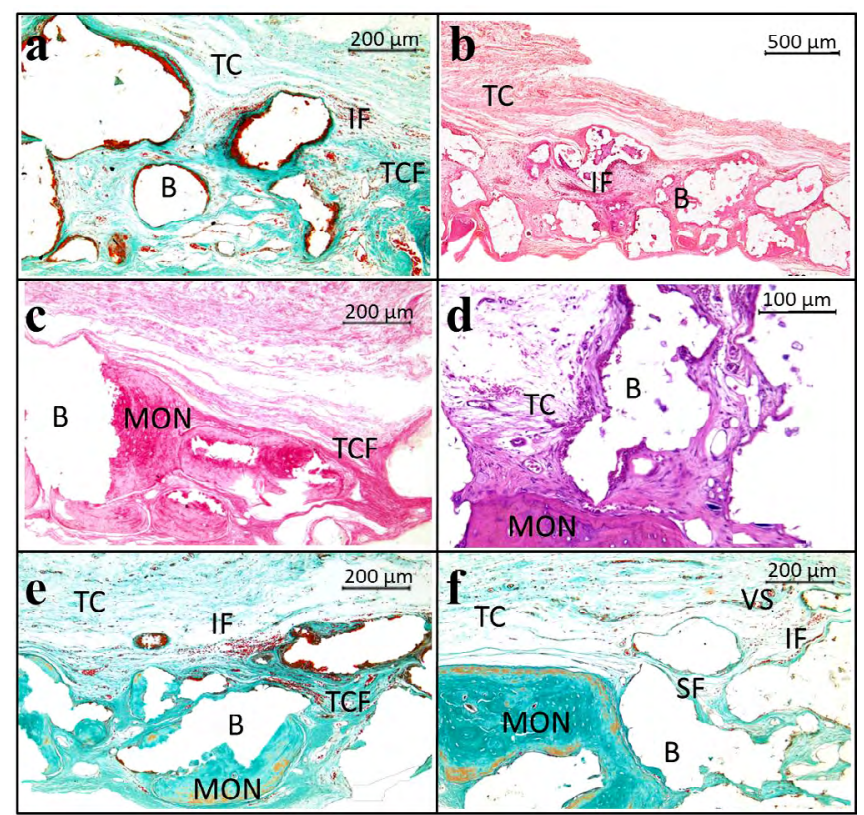

Figura 6: Fotomicrografias do reparo nos grupos em que houve implantação dos biomateriais (B): a) FCB em TMG; b) FCB/ BV em PIFG; c) FCB em HE; d) FCB/BV em HE; e) FCB em TMG; f) FCB/BV em TMG. Imagens mostram a organização do tecido conjuntivo (TC), onde é possível observar discreta reação inflamatória (IF) aos 45 dias (a,b). Aos 120 dias esta inflamação apresentava-se diminuta ou quase inexistente, porém o tecido conjuntivo ainda se encontrava edemaciado (c-f) e tornou-se fibroso (TCF) em FCB (c,e). No decorrer do tempo, as partículas dos biomateriais (B) que se encontravam envolvidas por septos de tecido fibroso (SF) foram substituídas por matriz osteoide neoformada (MON).

[Figure 6: Photomicrographs of the repair in the groups in which the biomaterials were implanted (B): a) FCB in $T M G$; b) $F C B / B V$ in PIFG ; c) FCB in $\mathrm{HE}$; d) FCB/BV in $\mathrm{HE}$; e) FCB in TMG ; f) FCB/ $B V$ in TMG. The images show the connective tissue organization (TC), where it is possible to observe a slight inflammatory reaction (IF) after 45 days $(a, b)$. After 120 days, this inflammation was small or almost nonexistent, but the connective tissue was still swollen (c-f), and became fibrous (TCF) in FCB (c,e). Over time, the particles of biomaterials $(B)$ that were surrounded by fibrous tissue septa $(S F)$ were replaced by a neoformed osteoid matrix (MON).]

para o entendimento do processo de reparo ósseo após implantação dos biomateriais à base de $\beta$-fosfato tricálcico/ pirofosfato de cálcio e vidro bioativo fosfatado, uma vez que possibilitou identificar a biocompatibilidade, capacidade dos biomateriais para promover a angiogênese, direcionar a adesão, migração e proliferação celular, além de avaliar sua biodegradação e bioabsorção, características essenciais para regeneração óssea.

\section{CONCLUSÕES}

Os materiais avaliados neste estudo foram biocompatíveis, atuaram como arcabouços tridimensionais, apresentaram potencial osteocondutor e favoreceram a regeneração óssea, principalmente os grânulos de fosfato 
de cálcio bifásico. A adição do vidro bioativo fosfatado aumentou a biodegradabilidade dos grânulos de fosfato de cálcio bifásico/vidro bioativo, todavia não favoreceu uma maior regeneração óssea. Ambas as composições testadas são propícias para utilização como substitutos ósseos.

\section{AGRADECIMENTOS}

Ao Instituto Militar de Engenharia por ceder os biomateriais utilizados; à Universidade Estadual de Feira de Santana por disponibilizar o biotério para realização dos experimentos; ao Instituto de Patologia Geral e Cutânea por viabilizar o processamento das amostras e à Fundação de Amparo à Pesquisa do Estado da Bahia pela bolsa de estudos e financiamento deste trabalho.

\section{REFERÊNCIAS}

[1] S. Allegrini Júnior, A.C. Silva, M. Tsujita, M.B. Salles, S.A. Gehrke, F.J.C. Braga, Microsc. Res. Tech. 81 (2018) 1. [2] S. Dasgupta, K. Maji, S.K. Nandi, Mater. Sci. Eng. C 94 (2019) 713.

[3] D.F. Williams, The Williams dictionary of biomaterials, Liverpool Un. Press, Liverpool (1999).

[4] D.F. Williams, Biomaterials 30 (2009) 5897.

[5] R.Z. LeGeros, Clin. Orthop. Relat. Res. 395 (2002) 81.

[6] W. Zhang, D. Yao, Q. Zhang, J.G. Zhou, P.I. Lelkes, Biofabrication 2 (2010) 1.

[7] J.S. Sun, W.H.S. Chang, L.T. Chen, Y.C. Huang, L.W. Juang, F.H. Lin, Biomaterials 25 (2004) 607.

[8] J.H. Lee, B.S. Chang, H.S. Ryu, C.K. Lee, Drug Chem. Toxicol. 32, 3 (2009) 277.

[9] D.W. Kim, J.S. An, I.S. Cho, Ceram. Int. 44 (2018) 9689.

[10] I.K. Karoussis, K. Kyriakidou, J. Papaparaskevas, I.A. Vrotsos, M. Simopoulou, G.A. Kotsakis, J. Biomed. Mater. Res. Part. B Appl. Biomater. 106, 7 (2018) 2645.

[11] M. Gutierres, M. Ascensão Lopes, N. Sooraj Hussain, A. Trigo Cabral, L. Almeida, J. Domingos Santos, Arq. Med. 19 (2005) 153.

[12] J.R. Jones, Acta Biomater. 23 (2015) S53.

[13] D. Navarro da Rocha, R.L.S.B. Marçal, R.M. Barbosa, J.R.M. Ferreira, M.H. Prado da Silva, Biomater. Med. Appl. 1, 2 (2018) 2.

[14] M. Elbadawi, Z.J. Wally, I.M. Reaney, J. Am. Ceram. Soc. 101 (2018) 3541.

[15] C. Carlo, B. Borges, A. Pacheco, D.F. Rezende, C. Maria, C. Lopes, C. César, S. Pontes, K. Cristine, S. Duarte, Rev. Ceres. 54, 316 (2007) 492.

[16] M.H. Prado da Silva, C.M. Ramirez, J.M. Granjeiro, A.M. Rossi, Key Eng. Mater. 361 (2008) 229.

[17] D. Navarro da Rocha, L.R.O. Cruz, J.L. Prado Neto, N.M.E. Ayad, L.A. Gobbo, M.H. Prado da Silva, Key Eng.
Mater. 587 (2014) 128.

[18] F.B. Miguel, A.A. Barbosa Júnior, F.L. Paula, I.C. Barreto, G. Goissis, F.P. Rosa, J. Mater. Sci. Mater. Med. 24 (2013) 2567.

[19] A.K.M.V. Cardoso, A.A. Barbosa Jr, F.B. Miguel, E. Marcantonio, M. Farina, G.D.A. Soares, F.P. Rosa, Cells Tissues Organs 184 (2007) 128.

[20] R.S. Almeida, I.I.A. Ribeiro, M.H. Prado da Silva, D. Navarro da Rocha, F.B. Miguel, F.P. Rosa, Rev. Ciên. Méd. Biol. 13, 3 (2014) 331.

[21] S.V. Dorozhkin, Biomaterials 31 (2010) 1465.

[22] R. Mulongo-Masamba, T. El Kassri, M. Khachani, S. Arsalane, M. Halim, A. El Hamidi, J. Therm. Anal Calorim. 124, 1 (2016) 171.

[23] A.D. Anastasiou, S. Strafford, O. Posada-Estefan, C.L. Thomson, S.A. Hussain, T.J. Edwards, Mater. Sci. Eng. C 75 (2017) 885.

[24] J.H. Lee, B.S. Chang, U.O. Jeung, K.W. Park, M.S. Kim, C.K. Lee, Clin. Orthop. Surg. 3, 3 (2011) 238.

[25] T. Ariizumi, H. Kawashima, H. Hatano, T. Yamagishi, N. Oike, T. Sasaki, H. Umezu, Y. Xu, N. Endo, A. Ogose, J. Biomater. Nanobiotechnol. 10, 3 (2019) 159.

[26] D. Navarro da Rocha, M.H. Prado da Silva, J.B. Campos, R.L.S.B. Marçal, D.Q. Mijares, P.G. Coelho, L.R. Cruz, J. Mater. Res. Technol. 7, 4 (2018) 479.

[27] G.M. Cooper, M.P. Mooney, A.K. Gosain, G. Phil, J.E. Losee, J. Huard, Plast. Reconstr. Surg. 125, 6 (2011) 1685.

[28] A. Neamat, A. Gawish, A.M. Gamal-Eldeen, Arch. Oral Biol. 54 (2009) 1083.

[29] D. Apelt, F. Theiss, A.O. El-Warrak, K. Zlinszky, R. Bettschart-Wolfisberger, M. Bohner, S. Matter, J.A. Auer, B. von Rechenberg, Biomaterials 25 (2004) 1439.

[30] S. Jensen, N. Broggini, E. Hjorting-Hansen, R. Schenk, D. Buser, Clin. Oral Implants Res. 17, 3 (2006) 237.

[31] M.M. Ferreira, A.F. Brito, C.F. Marques, L.F. Freitas, E. Carrilho, A.M. Abrantes, Ceram. Int. 44 (2018) 5025.

[32] D.G. Wang, C.Z. Chen, X.X. Yang, X.C. Ming, W.L. Zhang, Ceram. Int. 44 (2018) 14528.

[33] S.D. de Campos, É.A. de Campos, C.B. da Silveira, R.A. Bini, Cerâmica 51, 319 (2005) 274.

[34] T. Zambanini, R. Borges, P.C. Faria, G.P. Delpino, I.S. Pereira, M.M. Marques, J. Marchi, Int. J. Appl. Ceram. Technol. 16, 5 (2019) 2028.

[35] J.M. Anderson, Annu. Rev. Mater. Res. 31 (2001) 81. [36] J.M. Anderson, A. Rodriguez, D.T Chang, Semin. Immunol. 20, 2 (2008) 86.

[37] K.J.L. Burg, S. Porter, J.F. Kellam, Biomaterials 21 (2000) 2347.

[38] T. Albrektsson, C. Johansson, Eur. Spine J. 10 (2001) 96.

(Rec. 26/12/2018, Rev. 23/09/2019, 01/11/2019, Ac. $05 / 11 / 2019)$ 